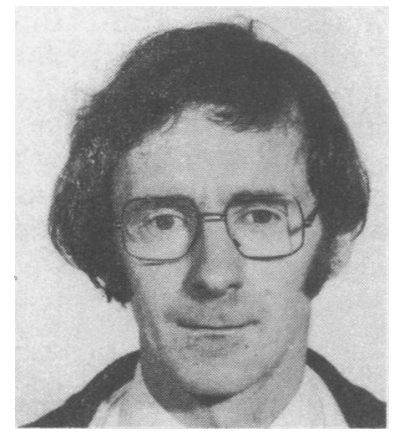

T. Reilly

\title{
PHYSIOLOGICAL, PSYCHOLOGICAL AND PERFORMANCE MEASURES DURING AN ENDURANCE RECORD FOR 5-A-SIDE SOCCER PLAY
}

\author{
T. REILLY, PhD and T. J. WALSH, BSc
}

Department of Sport and Recreation Studies, Liverpool Polytechnic, Byrom Street, Liverpool, L3 3AF

\begin{abstract}
Observations were made every $4 \mathrm{~h}$ on 2 teams during $91 \mathrm{~h} 45 \mathrm{~min}$ of 5 -a-side soccer to investigate stresses on players. Variables monitored were subjective fatigue, state anxiety, grip strength, heart rate, activity, urine protein concentration and liquid intake. Circadian functions were identified in all variables except protein urine as well as significant intercorrelations. Periodicities were consistent with arousal theory with troughs at about 0500-0600 $\mathrm{h}$ and crests at $1800 \mathrm{~h}$ to $2100 \mathrm{~h}$. Group mean anxiety values increased between days as play was prolonged whilst significant decrements were found in activity, exercise heart rate and urine protein. Mean heart rate for the duration of play was $98( \pm$ S.D. $=10)$ beats $\mathrm{min}^{-1}$ and the work severity was considered light. Behavioural abnormalities as found by other investigators in chronically sleep deprived subjects were common during the final two nights.
\end{abstract}

KEY WORDS: arousal, circadian rhythm, sleep deprivation, soccer.

\section{INTRODUCTION}

The crave to explore the limits of human capabilities has led to the evolution of manifold competitive activities and sports. A recent divergence from conventional competitive events has been the proliferation of attempts to endure performance in specific activities indefinitely. The development gained impetus with the establishment of "Guinness Superlatives", an independent institution set up to authenticate endurance records in a variety of continuous human activities and publish current records annually. The stresses on individuals in these record attempts have aroused much speculation but little investigation.

The physiological limitations to endurance performance have been the subject of numerous studies. Limiting factors include aerobic power (Saltin and
Åstrand, 1967), availability of substrate (Saltin, 1973), circulatory efficiency (Costill, 1972), thermoregulatory load (Costill, 1968) or strain on inert articuloskeletal structures (Wilkie, 1960). It is also probable that consideration of psychological factors is appropriate (Ogilvie, 1968). In events extending through the night effects of sleep deprivation may limit performance. Little research effort has however been devoted to events of this duration which include, for example, $24 \mathrm{~h}$ fell races and long distance rally drives, as well as aspiring entries to the "Guinness Book of Records".

Risks attendant with exercise continued over days may to an extent be anticipated. It is unlikely that work can be sustained at a high intensity over this period. Lloyd et al (1977) reported proteinuria in athletes attempting a $24 \mathrm{~h}$ relay run world record. With work 
intensity reduced to a constant oxygen uptake demand of $15 \mathrm{ml} / \mathrm{kg} / \mathrm{min}^{-1}$ Thomas and Reilly (1975) reported that exercise can be continued for up to $100 \mathrm{~h}$ under conditions of controlled energy intake. However psychomotor performance and motivational state showed deteriorating trends over that period. The effects of sleep deprivation on performance can vary from nil to almost complete breakdown depending on the nature of the task and the motivation of the subject (Wilkinson, 1964). When sleep loss is suffered for $100 \mathrm{~h}$ frank psychotic symptoms appear of the paranoid-schizoid type with emotional lability and delusions of grandeur and persecution (West et al, 1962). It is hardly coincidental that biochemical transfer systems have been found to break down at this stage (Luby et al, 1960). It has long been known that sleep-deprived subjects suffer hallucinatory experiences before this point (Patrick and Gilbert, 1896).

Kleitman (1963) found that the effect of staying awake for several days did not manifest itself in a continual psychological deterioration but instead a waxing and waning with the succession of days and nights was exhibited. The cyclical fluctuations reflect circadian rhythms in underlying physiological mechanisms (Conroy and Mills, 1970). Sleep deprivation tends to lower body temperature but without affecting its $24 \mathrm{~h}$ rhythm (Kleitman and Jackson, 1950). Performance under conditions of sleep deprivation tends in general to follow its normal circadian cycle with some authors reporting a greater time of day effect due to deprived sleep (e.g. Colquhoun, 1971). Circadian rhythm may be swamped in conditions that demand a constant level of power output (Thomas and Reilly, 1975). Physical activity during the night has been found useful by experimenters to offset to some extent the effects of chronic sleep loss on subjects (Kleitman, 1963). Where this activity must be spontaneously generated by the subjects the underlying physiological predispositions to circadian rhythm should prevail. It is reasonable to hypothesise that customary performance rhythms would be exhibited. This research was undertaken:

(i) to monitor the stresses on a group of footballers attempting an endurance record for 5-a-side play and so provide basic data on the demands of this type of prolonged activity;

(ii) to study the interactions between sleep deprivation and circadian rhythm under such conditions of self-paced work.

\section{METHODS}

Ten male polytechnic students aged $21-23$ acted as subjects in an attempt to play 5-a-side football for beyond the current record of $81.03 \mathrm{~h}$ (McWhirter, 1978). The attempt commenced at $0900 \mathrm{~h}$ and the objective was to continue to play for $100 \mathrm{~h}$. The regulations governing the event required that play be continuous apart from a $5 \mathrm{~min}$ rest period every $50 \mathrm{~min}$.
Sustenance and injury treatment were not permitted except during this break. Subjects could eat and drink ad libitum during the intermission, provisions being prepared in advance by a group of assistants. No substitution of players was permitted. Play was supervised by referees acting in shifts and the normal rules for indoor football applied. Players were identified by numbers on their shorts and shirts while teams were distinguished by green (Team 1) and yellow (Team 2) colours. In the playing environment used it was impossible to eliminate temporal cues as to the normal $24 \mathrm{~h}$ forcing rhythm.

\section{TESTS}

Data was collected by two experimenters working in overlapping shifts. Tests were conducted during the intermission at $4 \mathrm{~h}$ intervals throughout the attempt and staggered so that they did not coincide. These included:

(i) subjective fatigue - subjects were asked to rate perceived fatigue on a 5 point scale from very fresh, somewhat fresh, OK, somewhat tired, to very tired;

(ii) psychological state - determined using the Spielberger self-evaluation questionnaire (Spielberger, Gorsuch and Lushene, 1976);

(iii) grip strength - measured according to Clarke (1967) by grip dynammometry in Team 2 only. The dominant hand only was tested.

\section{Match-play measures}

(i) Heart rate: was monitored in the 4 outfield players in Team 1 during play by means of radio telemetry (NEC Type 101). These players were fitted before starting with electrodes attached to a radio transmitter on the waistband of their shorts. Heart rate was sampled every $10 \mathrm{~s}$ over $5 \mathrm{~min}$ for each of the 4 subjects once every $4 \mathrm{~h}$ and the mean of the pooled data used to indicate the level of physiological strain for that period of play.

(ii) Activity: was recorded using a modified motion analysis method (Reilly and Thomas, 1976). The time spent standing, walking and running at 3 intensity levels by the 4 outfielders in Team 1 was measured, each subject being observed for $5 \mathrm{~min}$ every $4 \mathrm{~h}$. The proportion of the time spent active was calculated.

In addition volumes of liquid intake were recorded. Urine was collected in $0.57 \ell$ containers and analysed for protein using Albustix.

\section{Statistical Analysis}

A two way ANOVA was used to investigate differences between days and time of day effects. Each day was considered to commence at $0900 \mathrm{~h}$. Significant results 
between days were further explored using Tukey's HSD test (Kirk, 1968). Since timing of liquid ingestion was at irregular periods, data was pooled to constitute separate day-time (0900-2100 h) and night-time (2100$0900 \mathrm{~h}$ ) values before analysis using ANOVA. Intercorrelations between mean values of variables monitored every $4 \mathrm{~h}$ were investigated using the Pearson Product Moment method of correlation.

\section{RESULTS}

Play commenced at $0900 \mathrm{~h}$ and was maintained for $91 \mathrm{~h} 45$ min until terminated by the referee when continuation of meaningful activity was adjudged impractical. At that time overt effects of sleep deprivation were pronounced with recurring instances of behavioural abnormality among players. Two individuals had experienced visual hallucinations by the second night while all players hallucinated visually on subsequent nights. Serious competition between the teams was difficult to sustain throughout the night after $60 \mathrm{~h}$. Periodically during the third and fourth nights meaningful involvement in the game by individual players was restricted by transient schizoid behaviour.

A pronounced circadian variation was apparent in the ratings of subjective fatigue shown in Figure 1. ANOVA results showed a significant circadian effect ( $p<.01$ ) but differences between days were non-significant $(p>$.05). Peak fatigue consistently occurred between $0100 \mathrm{~h}$ and $0500 \mathrm{~h}$ and lowest values between $1700 \mathrm{~h}$ and $2100 \mathrm{~h}$. Periodicity in fatigue appeared less marked over the final day of sleep deprivation.

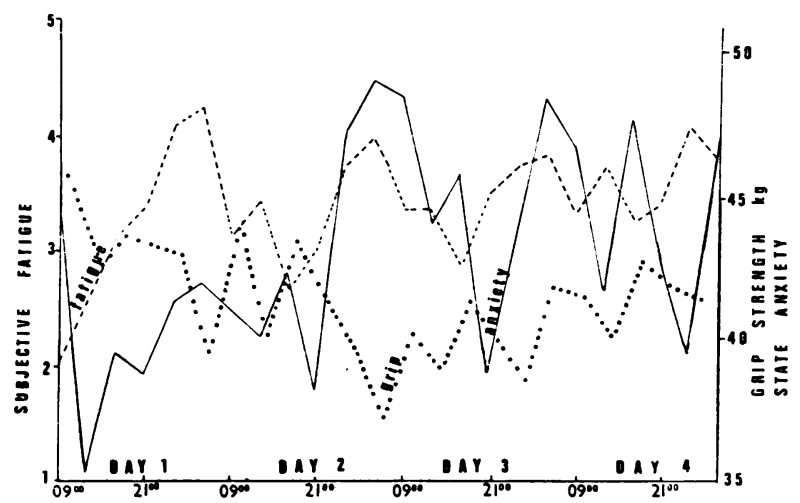

Figure 1: Mean values for players for each measurement period of subjective fatigue, grip strength and state anxiety monitored at $4 \mathrm{~h}$ intervals. The fatigue scale is indicated on the left, the grip strength on the right vertical axis. The mean state anxiety data is expressed in arbitrary units corresponding with the grip strength scale.

Mean state anxiety data are presented in Figure 1. The ANOVA results showed significant variation between times of day $(p<.05)$ and between days $(p<.05)$. Circadian variation appeared to be bi-modal with daily peaks at $0500 \mathrm{~h}$ and at $1700 \mathrm{~h}$. Troughs in state anxiety occurred at $1300 \mathrm{~h}$ and $2100 \mathrm{~h}$. Mean anxiety was high at commencement of the record attempt but had decreased significantly after $4 \mathrm{~h}$ play $(p<.01)$. The mean level for Day 1 was significantly lower than the means for Day 3 and Day $4(p<.05)$ which in turn did not differ significantly from each other $(p>$.05). The Day 2 mean did not differ significantly from any of the other days $(p>.05)$. Most subjects took longer to complete the questionnaires during the latter part of the record attempt, experiencing lapses in concentration especially during the early morning hours.

Mean grip strength results are included along with subjective fatigue and state anxiety in Figure 1. ANOVA found significant results for both circadian and between day effects $(p<.05)$. A bi-modal circadian cycle was observed with peaks at $1000 \mathrm{~h}$ and $1800 \mathrm{~h}$ and troughs at $0600 \mathrm{~h}$ and $1400 \mathrm{~h}$. Tukey's range test showed that grip strength deteriorated over the second day while the Day 3 mean also differed significantly from the Day 1 value $(p<.05)$. None of the other pairwise comparisons gave significant results $(p>.05)$.

The mean heart rates during play for outfielders in Team 1 are presented in Figure 2. Significant results were found for both time of day and between day effects $(p<.01)$. Circadian rhythm was apparent in the data with peaks each day at $1800 \mathrm{~h}$ and troughs at $0600 \mathrm{~h}$. Initially heart rates were high $(\sim 120$ beats $\mathrm{min}^{-1}$ ) considering the time span of performance. The

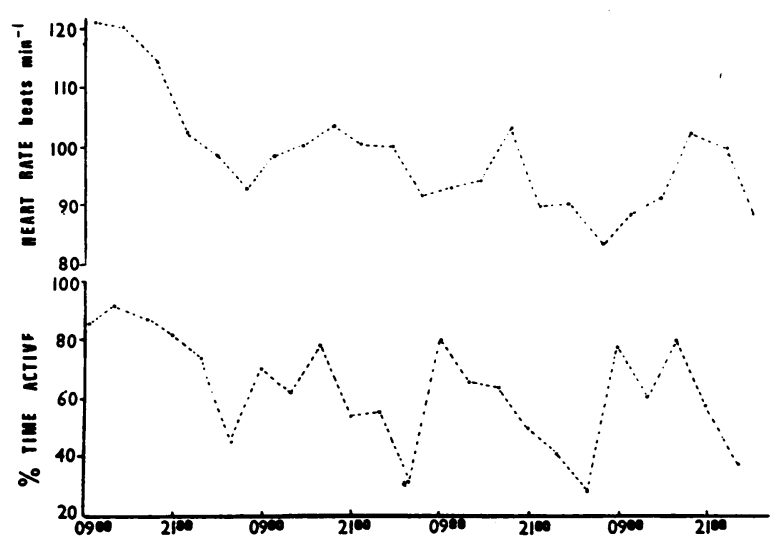

Figure 2: Mean heart rate and percent time active in 4 outfield players every $4 \mathrm{~h}$. For each measurement period all data points on each of the 4 subjects were pooled to obtain the mean values shown. Monitoring of heart rate lagged the activity measurement by $1 \mathrm{~h}$. Progression on the horizontal axis indicates successive days of play. 
mean for Day 1 was significantly higher than for each of the remaining days $(p<.01)$ which did not differ significantly from each other $(p>.05)$. The mean heart rate for the group over the complete playing period was $98( \pm S D=10)$ beats $\mathrm{min}^{-1}$.

The pattern of activity as presented in Figure 2 showed similar trends in exercise intensity to that suggested by the heart rate data, the monitoring of heart rate lagging the activity measurement by $1 \mathrm{~h}$. The percentage time spent moving varied significantly both between and within days $(p<.01)$. Time spent active showed a daily trough of $0500 \mathrm{~h}$ and a peak usually at $1700 \mathrm{~h}$, though values were elevated from $0900 \mathrm{~h}$ and a steep drop had occurred by $2100 \mathrm{~h}$ each day. Tukey's HSD test gave non-significant results for all the possible pairwise comparisons between days (p>.05).

Liquid intake volumes did not vary between days $(p>.05)$ but were greater during the day than at night $(p<.05)$. Peaks occurred between $1500 \mathrm{~h}$ and $1900 \mathrm{~h}$ and troughs between $2300 \mathrm{~h}$ and $0700 \mathrm{~h}$. The mean concentration of protein in urine is displayed in Figure 3. No circadian effect was found $(p>.05)$ but the difference between days was significant $(p<.05)$. Day 1 values were significantly greater than Day 2 $(p<.01)$, Day $3(p<.05)$ and Day $4(p<.01)$. Day 3 levels were significantly higher than Day $2(p<.05)$ and Day $4(p<.01)$. The elevation in mean at $64 \mathrm{~h}$ of play was largely attributable to elevated values in one subject at this time. This excessive proteinuria was accompanied by pronounced haematuria and was not found on the subsequent day. Analysis of variance ratios showed that the variance on Day 3 was significantly greater than that for each of the other days $(\mathrm{p}<.01)$.

Intercorrelations between variables are shown in Table 1. Subjective fatigue was highly correlated

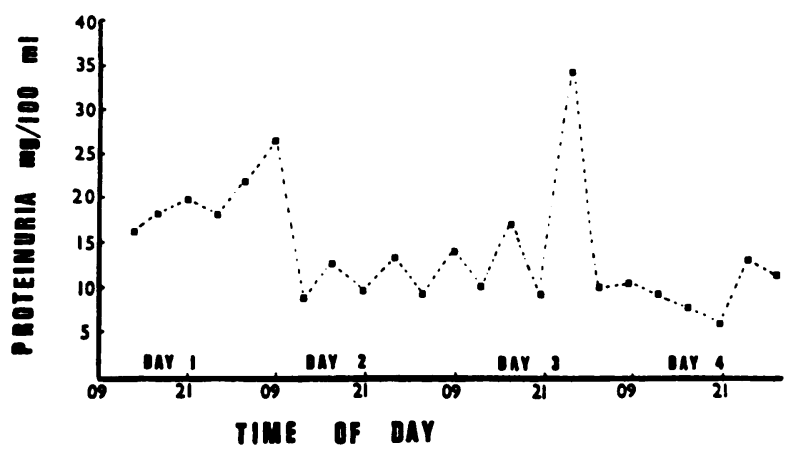

Figure 3: Mean proteinuria levels every $4 h$ with duration of play. The value shown at each point is the mean for all subjects' sampled in that measurement period.

negatively with grip strength and exercise intensity as reflected in heart rate and percent time active $(p<.001)$. The percent time active correlated positively with the volume of liquid ingested $(p<.05)$. A significant negative correlation was found between state anxiety and urine protein concentrations $(p<.05)$.

\section{DISCUSSION}

The behaviour of subjects conformed in general to that described by other investigators in sleep deprivation studies. Cyclic variations persisted in the majority of parameters monitored rather than a continual deterioration as a result of staying awake. Subjects seemed to endure the first night of wakefulness easily apart from a spell of drowsiness between $0300 \mathrm{~h}$ and $0600 \mathrm{~h}$. On subsequent nights reactions appeared worse with com. plaints of itchy and dry eyes, extreme sleepiness being encountered during the early hours of the morning. After the first night most subjects were more irritable and aggressive in play. Two wished to desist during the second night but were persuaded otherwise by their

\section{TABLE 1}

\section{Correlation matrix between variables}

\begin{tabular}{|c|c|c|c|c|c|c|c|}
\hline & Fatigue & Anxiety & Grip & Heart Rate & \% Time Active & Proteinuria & Liquid Intake \\
\hline Fatigue & 1.00 & .20 & $-.70^{* * *}$ & $-.76^{* * *}$ & $-.69 * * *$ & .17 & -.38 \\
\hline Anxiety & & 1.00 & -.33 & -.37 & -.28 & $-.44 *$ & -.06 \\
\hline Grip & & & 1.00 & $.63^{* * *}$ & $.66 * * *$ & -.05 & .29 \\
\hline Heart Rate & & & & 1.00 & $.73^{* * *}$ & .05 & .17 \\
\hline$\%$ Time Active & & & & & 1.00 & -.02 & $.46^{*}$ \\
\hline Proteinuria & & & & & & 1.00 &.$- \dot{3} 3$ \\
\hline Liquid Intake & & & & & & & 1.00 \\
\hline
\end{tabular}

For each measurement period data was pooled for all subjects and the mean value used in the correlation analysis. As measurements were made every $4 \mathrm{~h}$, each discrete analysis involved 22 observations on each variable.

(* denotes $\mathrm{P}<.05 ;$; denotes $\mathrm{P}<.01$; * * denotes $\mathrm{P}<.001$ ) 
colleagues. Hypnagogic states and visual hallucinations were common after the second night. Individual players proved difficult to motivate during the final two nights when effective enthusiasm for the game dwindled. Group morale was obviously low at these times and might have been improved by provision of background stimuli such as attendance of spectators or playing of loud music. It seems commitment to meaningful competition becomes difficult to sustain in record attempts of this nature because of increasing boredom and occurrence of transient psychotic-like behavioural episodes with lack of sleep. Though abnormal behaviour was exhibited periodically during play and was marked when play was terminated no enduring ill-effects were reported. All players attended classes $30 \mathrm{~h}$ after finishing and, on unstructured interview, demonstrated apparent complete recovery.

The significant correlations between fatigue, grip strength, heart rate and activity support the finding that circadian rhythms persisted and suggest that they were largely in phase concordance. Though measurement of all four variables was not synchronous results indicated concurrent cyclic drifts in performance with minima around $0500 \mathrm{~h}-0600 \mathrm{~h}$ and maxima at $1800 \mathrm{~h}$ to $2100 \mathrm{~h}$. These are in close agreement with arousal theory predictions that performance follows shifts in indicants of physiological arousal, body temperature being considered the fundamental variable (Hockey and Colquhoun, 1970). The circadian curve in body temperature is well documented with minima at about $0500 \mathrm{~h}$ and maxima around $1900 \mathrm{~h}$ to $2100 \mathrm{~h}$ (Colquhoun, 1971) and corresponds with the circadian performance curves observed in this study. Results are also in agreement with those of Morgan and colleagues (1974) who found that physical performance was lowest during the early morning hours and highest during the daytime in subjects undergoing sleep deprivation for $48 \mathrm{~h}$. It seems that innate circadian rhythms are reflected in performance when activity is continued over abnormal periods of wakefulness. In future records attempts it would seem helpful to provide special encouragement during the early morning hours when arousal is low and performance slumps. The abandonment of play of $0445 \mathrm{~h}$ in the current study further substantiates susceptibility of performers at this time of night.
The infradian drop in grip strength in the early afternoon corresponds with the 'post-lunch dip' phenomenon reported to persist in the absence of a customary midday meal (Colquhoun, 1971). The trough in state anxiety at around mid-day has been reported elsewhere for subjects undergoing their normal habitual regime while the crest at $1700 \mathrm{~h}$ coincided with the highest levels of anxiety in that investigation (Stockton et al, 1978). The second crest at $0500 \mathrm{~h}$ was probably associated with the feelings of discomfort and tiredness at that time of night. The elevated anxiety levels during the final two days accompanied the occurrence of uncharacteristic behavioural episodes. Urine protein levels were close to normal non-pathological values apart from the temporary elevation in one subject. The higher levels during the first day were probably due to the greater intensity of exercise with resultant increase in renal pressure. Homeostatic processes were reflected in the relationship between fluid intake and activity, fluid loss being expected to increase proportionally with work rate.

The negative correlation between subjective fatigue and grip strength, heart rate and activity was in the opposite direction to findings at high work intensities of short duration where accumulation of exercise induced metabolites within muscle limits performance (Gollnick and Hermansen, 1973). At low work intensities of prolonged duration increased feelings of fatigue might be expected to reduce the drive to perform physical work and result in lowered levels of circulatory strain. The mean heart rate of 98 beats $\mathrm{min}^{-1}$ over the period of play indicated that the work intensity was light according to conventional systems for classifying work severity (Christensen, 1953). This level was higher than the 84 beats $\mathrm{min}^{-1}$ over $100 \mathrm{~h}$ of continuous exercise reported by Thomas and Reilly (1975), or the range of 65 to 95 beats $\mathrm{min}^{-1}$ in swimming without sleep for 148.5 h (Osternig and Baer, 1976). Immersion bradycardia is likely to have operated in the swimming case-study though the correlation coefficient between heart rate and swimming rate was 0.64 for 1 of the 2 swimmers. It seems that provided subjects pace themselves to work at low levels of physiological strain performance can be endured for extended periods numbering in days rather than hours.

\section{REFERENCES}

Christensen, E. H., 1953 "Physiological valuation of work in the Nykroppa Iron Works". Symposium on Fatigue. W. F. Floyd and A. T. Welford, eds., H. K. Lewis, London.

Clarke, H. H., 1967. Application of Measurement to Health and Physical Education. Prentice Hall, New Jersey.

Colquhoun, W. P., 1971. Biological Rhythms and Human Performance. Academic Press, London. 
Conroy, R. T. W. L. and Mills, J. N., 1970. Human Circadian Rhythms. Churchill, London.

Costill, D. L., 1968. What Research Tells the Coach about Distance Running. AAHPER, Washington.

Costill, D. L., 1972 “Physiology of marathon running”. J.Amer.Med.Ass. 221: 1024-1029.

Gollnick, P. D. and Hermansen, L., 1975 "Biochemical adaptation to exercise: anaerobic metabolism". Exercise and Sports Science Reviews, Vol. 1. J. H. Wilmore, ed., Academic Press, New York.

Hockey, G. R. T. and Colquhoun, W. P., 1972 “Diurnal variation in human performance: a review". Aspects of Human Efficiency. W. P. Colquhoun, ed., English University Press, London.

Kirk, R. E., 1968. Experimental Design: Procedures for the Behavioural Sciences. Brooks/Cole Publishing Company, Belmont.

Kleitman, N. and Jackson, D. P., 1950 "Body temperature and performance under different routines". J.Appl.Physiol. 3: 309-328.

Kleitman, N., 1963. Sleep and Wakefulness. University of Chicago Press, Chicago.

Lloyd, E. L., Henderson, W., Lovell, B. and Bryce, G. R., 1977 "Factors affecting performance during an endurance relay". Brit.J.Sports Med. 11: 138-142.

Luby, E. D., Frohman, C. E., Grisell, J. L., Lenzo, J. E. and Gottlieb, J. S., 1960 "Sleep deprivation: effects on behaviour, thinking, motor performance and biological energy transfer systems". Psychosom.Med. 22: 182-192.

Morgan, B. B., Brown, B. R. and Alluisi, E. A., 1960 "Effects on sustained performance of 48 hours of continuous work and sleep loss.". Human Factors 16: 406-414.

McWhirter, N. D., 1978. Guinness Book of Records. Guinness Superlatives, London.

Ogilvie, B. C., 1968 "Psychological consistences within the personality of high level competitors". J.Amer.Med.Ass. 205: $780-785$.

Osternig, L. R. and Baer, C. L. H. Jr., 1976 “Physiological observations during prolonged swimming without sleep intervals". Physical Education, Sports and the Sciences. J. Broekhoff, ed., Microform Publications, University of Oregon.

Patrick, G. T. W. and Gilbert, J. A., 1896 "On the effects of loss of sleep". Psychol.Rev. 3: 469-483.

Reilly, T. and Thomas, V., 1976 "A motion analysis of work-rate in different positional roles in professional football match-play". J.Hum.Mov.Stud. 2: 79-86.

Saltin, B. and Åstrand, P. O., 1967 "Maximal oxygen uptake in athletes". J.Appl.Physiol. 23: 347-352.

Saltin, B., 1973 "Metabolic fundamentals in exercise". Med.Sci.Sports 5: 137-146.

Spielberger, C. D., Gorsuch, R. and Lushene, R. E., 1976 "State-trait anxiety inventory. Diagnostic tests and teaching aids". Consulting Psychologists Press, Palo Alto.

Stockton, I. D., Reilly, T., Sanderson, F. H. and Walsh, T. J., 1978 "Investigations of circadian rhythm in selected components of sports performance". Paper presented at the Society of Sports Sciences Conference, Crewe and Alsager.

Thomas, V. and Reilly, T., 1975 "Circulatory, psychological and performance variables during 100 hours of paced continuous exercise under conditions of controlled energy intake and work output". J.Hum.Mov.Stud. 1: 149-156.

West, L. J., Janszen, H. H., Lester, B. K. and Cornelisoon, F. S., 1962 "The psychosis of sleep deprivation". Ann. N.Y.Acad.Sci. 96: 66-70. 
Wilkie, P. R., 1960 "Man as a source of mechanical power". Ergonomics 3: 1-8.

Wilkinson, R. T., 1964 "Effects of up to 60 hours sleep deprivation on different types of work". Ergonomics 7: 175-186.

\section{OBITUARY}

\section{Dr. Maurice Livingstone Thomson}

It is with regret that we note the death of Dr. Maurice Thomson on 29th March, 1981, aged 73.

He was born in Lanarkshire, the son of the Manse, and obtained BSc Chemistry in 1929. After a short period of chemical research, he became a science teacher. Just before the war, he entered Glasgow University School of Medicine, and qualified in 1942.

He was a House Surgeon at the Western Infirmary, Glasgow, but joined the Royal Navy in 1943, and during service at sea became interested in problems of chloride balance and heat stress. This led to shore appointments at Cambridge and Singapore, and studies in cold environments were carried out after the war.

He retired from the Royal Navy in 1950, with the rank of Lieutenant Commander, and joined the Physiology Department at the London School of Hygiene and Tropical Medicine.

He became interested in the stresses due to exercise and in the climatic hazards of competing in sport in different environments, and was one of the earliest members of the Fitness and Training Section of the Ergonomics Research Society. He conducted a good deal of respiratory research in athletes and I first came across him when he was studying respiratory function in young Olympic possibles selected by the Amateur Swimming Association, for the Easter Course, which was held annually at Loughborough College of Education.

He joined the British Association of Sport and Medicine in 1962, and gave us helpful advice and loyal service until his resignation in 1971, at which time his interests were switched to other aspects of respiratory physiology.

I found Maurice Thomson a very stimulating and knowledgeable research worker who would, with patience and understanding, explain his techniques to those who were not experts in respiratory physiology, and proudly showed me his whole-body plethysmograph, which he constructed at the School of Hygiene.

His death will be a big loss to exercise physiology and we offer our sympathy to his wife and family.

H. E. Robson 